\title{
COMPARATIVE STUDY OF FUNCTIONAL OUTCOME BETWEEN PLANTAR FASCIA STRETCHING AND ACHILLES TENDON STRETCHING EXERCISES IN CHRONIC PLANTAR FASCIITIS
}

\author{
Shrestha S, $^{1^{*}}$ Rai $S,{ }^{2}$ Limbu $H^{3}$ Bajracharya $S^{4}$ \\ Lecturer, ${ }^{1}$ Lecturer, ${ }^{2}$ Associate Professor, ${ }^{3}$ Associate Professor ${ }^{4}$ \\ ${ }_{1,2,3,4}$ Department of Orthopaedics, KIST medical college, Imadol,
}

*Corresponding Author:

Dr Shriraj Shrestha, MBBS, MS (Ortho), Lecturer Department of Orthopaedics and Trauma surgery KIST Medical College, Imadol, Lalitpur.

E-mail: shrirajshrestha@gmail.com

\begin{abstract}
Background: Plantar fasciitis is a self limiting disease, with only $10 \%$ of patient developing chronic condition even after ten months. We hypothesized that patient with chronic plantar fasciitis who are treated with standard plantar fascia stretching program can have a better functional outcome than those treated with Achilles tendon-stretching exercise.
\end{abstract}

Method: Forty patients who had chronic plantar fasciitis for duration of at least ten months were randomized into one of two groups. Group A received plantar stretching exercise and Group B had Achilles tendon stretching program. All patients completed the pain subscale of Foot Function Index and a subject relevant outcome survey that incorporated generic and condition-specific outcome measures related to pain, function and satisfaction with treatment outcome.

Result: The pain subscale scores of the Foot Function Index showed significantly better results at eight weeks for the patients managed with plantar fascia stretching program respect to item 1 (worst pain; $p=0.004$ ) and item 2 (first steps in the morning; $p=0.001$ ). Similarly at ten months follow up, pain subscale score comparison was statistically significant for item $1(\mathrm{p}=0.018)$ and item $2(\mathrm{p}=0.003)$.

Conclusions: A treatment method of non-weight-bearing stretching exercises specific to plantar fascia is superior to the conventional method of weight-bearing Achilles tendon-stretching exercises for treating patients with chronic plantar fasciitis.

Keywords: Achilles tendon stretching exercise; chronic plantar fasciitis; plantar fascia stretching exercise.

\section{BACKGROUND:}

Plantar fasciitis is a common cause of heel pain ${ }^{1}$. It is regarded as an inflammation of plantar fascia, which is a strong band of fibers arising from medial calcaneal tuberosity fanning out to plantar plates of the metatarsal joints and bases of the phalanges ${ }^{2}$. Heel pain of spontaneous onset more during the early few steps in the morning or after a period of inactivity is the classical presentation ${ }^{3}$.

Most patients have spontaneous resolution of symptoms but about $10 \%$ tent to chronic symptoms ${ }^{4}$. Though both surgical and non surgical approaches are available for management, nonsurgical approaches are generally considered as first line ${ }^{5,6,7}$. Use of night splint to keep foot in dorsiflexion, ultrasound massage, custom designed shoes, prefabricated soft insoles, achilles tendon stretching exercise and plantar fascia stretching exercise are some of the available options.

Achilles tendon stretching exercise was evaluated in management of chronic plantar fasciitis and found to be 
useful $^{8}$. Another study compared Achilles tendon stretching exercise and plantar fascia stretching exercise and found plantar fascia stretching exercise to be superior ${ }^{4}$. In this study however all patients had received prefabricated soft sole inserts along with exercise program. Predesigned soft sole inserts are not easily available to our patients in developing country like Nepal. We designed this study to asses the efficacy of plantar fascia stretching exercise and Achilles tendon stretching exercise without the use of soft insole in management of chronic plantar fasciitis. The aim of the study was to compare the effectiveness of non weight bearing stretching exercise specific to plantar fascia alone and weight bearing Achilles tendon stretching exercise alone for both short and long duration in Nepalese population who have different terrain and footwear habits.

\section{Methods:}

This is an experimental study carried out in the department of orthopaedics and trauma surgery of KIST Medical College Teaching Hospital, Imadole, Lalitpur, Nepal from july 2012 to july 2013. Necessary permission was taken from the ethical committee of the hospital and informed consent was taken from the patients.

Total of 40 patients with chronic plantar fasciitis of both gender above 16 years whose symptoms persisted for at least ten months duration, with maximum pain upon palpation of the origin of plantar fascia on the medial calcaneal tubercle were included in the study. The exclusion criteria were patient with Diabetes, Gout, Connective tissue disorder, Calcaneal fracture, prior heel surgery and heel pain that were not consistent with chronic plantar fasciitis.

After thorough physical examination, clinical diagnosis was made and patients who met the inclusion criteria for the study were alternatively allocated to either group A (Plantar fascia stretching exercise) or group B (Tendo Achilles stretching exercise).

Once enrolled in the study all baseline data including age, gender, height, weight, hours spend standing during the day, duration of symptoms and type of prior treatment were collected. Patients were asked to complete the pain subscale of Foot Function Index. The patients were advised to discontinue all ongoing therapy that they were receiving for the heel pain. They were advised to continue with their regular shoe wear and activity level.

Group A, received instructions in a plantar fasciia tissuestretching method. They were instructed to perform the exercise while sitting and by first crossing the affected leg over the contralateral leg. Then, while using the hand on the affected side, they had to place the fingers across the base of the toes on the bottom of the foot (distal to the metatarsophalangeal joints) and pull the toes back toward the shin until they felt a stretch in the arch of the foot. They were taught to confirm that the stretching was correct by palpating the tension in the plantar fascia with the contralateral hand while performing the stretch. The first stretch was to be conducted before taking first step in the morning.

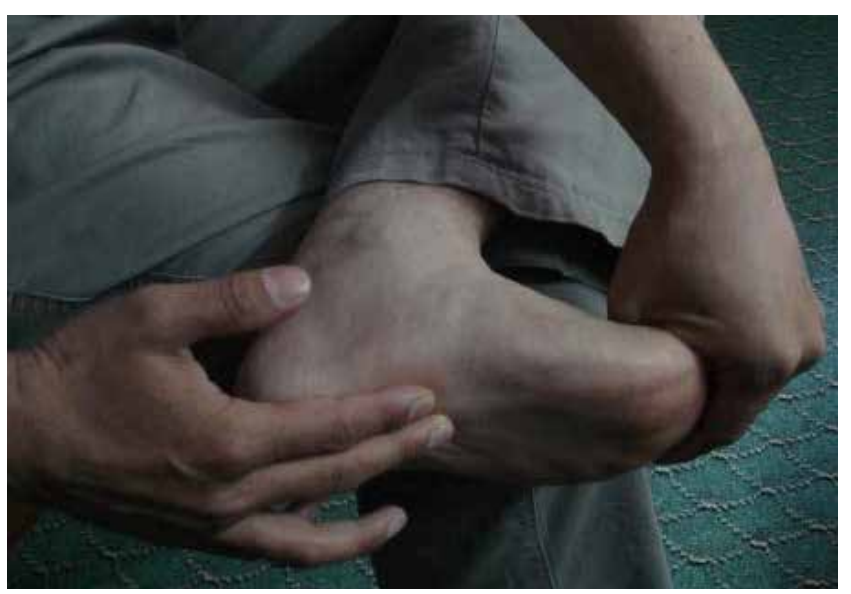

Figure1: Plantar fascia stretching exercise

Group B, received instructions in an Achilles tendonstretching method. They were taught to perform the exercise while standing and leaning into the wall with the affected leg placed behind the contralateral leg. Patients were specially instructed to avoid excessive midfoot pronation while stretching. They were also instructed to "toe in" or point the toes of the affected foot toward the heel of the front foot. Patients were told to bend the front knee while keeping the back knee straight and the heel firmly on the ground. First step was to be conducted immediately after getting out of bed in the morning.

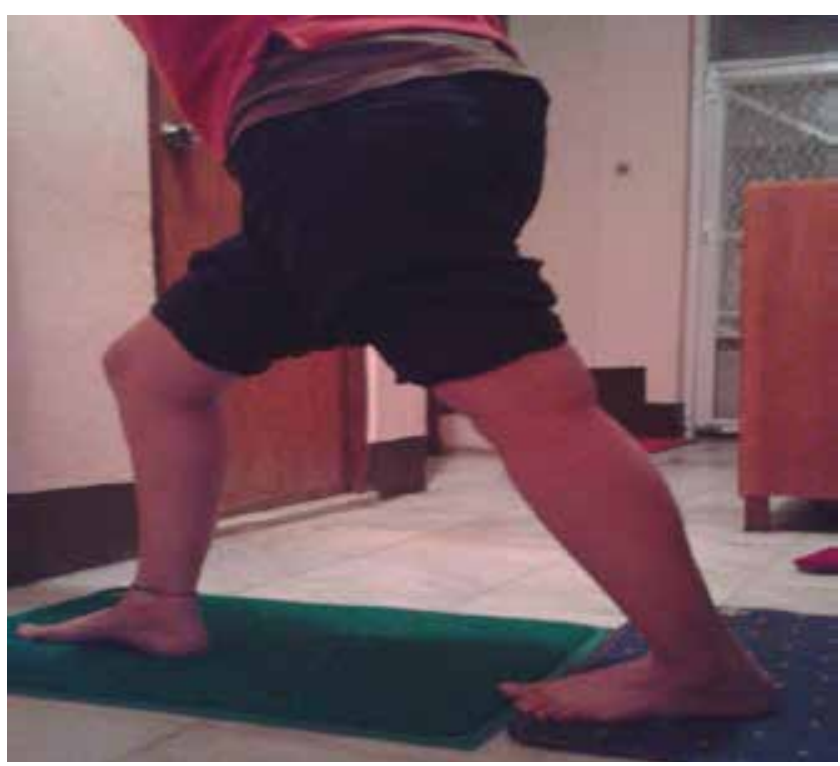

Figure 2: Achilles tendon-stretching exercise. 
Patients in both groups were instructed to hold each stretch for a count of twenty and to repeat it twenty times, two times I day. Patients from both group were taught the procedure and were requested to perform the exercise in OPD before being given a hand out of the stretching technique containing diagrammatic instruction and were asked to keep a daily log of exercise completion through a mini calendar provided to them at the start of treatment.

First follow up was scheduled at four weeks. Those who did not show up were contacted by telephone. At this period, queries, regarding treatment outcomes and compliances with the exercise were made. Second follow up was done at eight weeks. Assessment and completion of the pain subscale of the Foot Function Index and a subject-relevant outcome measures was done.

Final follow up was done at ten months and full assessment including relapse was carried out.

Questions from the pain subscale of the Foot Function Index were used to generate the primary numeric outcome scores. The questions were scored from 0 (no pain) to 10 (worst pain imaginable), depending on the location marked by the patients on the visual analog scale. The change in the overall pain score - that is, the score after eight weeks minus the baseline score for post procedure and score after 10 months minus the baseline score for follow up was used for subsequent analysis. A negative change in the visual analog scale score signified patient improvement. Additionally, the numeric scores for the first two items on the pain subscale were selected as a priority to be evaluated separately, as these represented the disease defining clinical findings.

Since pain response is a subjective matter, patients satisfaction was assessed separately on Subject related Outcome measures scale which originally was used by Digiovani et $\mathrm{al}^{5}$. So at the follow-up visit, patients were asked to rate the change in pain between the initial and follow-up visits as well as their perceptions of overall improvement since beginning of the study. In order to simplify the interpretation of the analyses, the responses to the questions on the subject-relevant outcome measures were split into positive or negative response. Positive response included (total satisfaction, satisfaction with minor reservations and $>50 \%$ improvement from the initial assessment). Negative response included (dissatisfaction, satisfaction with major reservation and $<50 \%$ improvement from the initial assessment).The overall result obtained predominantly positive response or predominantly negative response.

The data obtained from Foot Function Index were analyzed using standard statistical procedure (independent $\mathrm{t}$ test, chi square test).

\section{Result:}

All patients were in the age range of 21 to 50 years. Majority of the patients were female, accounting for $72 \%$ of the total patients under study. In our study the majority of patients, $67 \%$ were in the range of 41 to $60 \mathrm{Kg}$ and remaining $33 \%$ in the range of 60 to $80 \mathrm{~kg}$. Amongst these patients, $80 \%$ were in the Body Mass Index range of 20 to 25 . There were equal distribution of patients with BMI in range of 26 to 30 and those with $<20$, both accounting to $10 \%$ each. Majority of patients $(80 \%)$, had standing hours 5 to $8 \mathrm{hrs}$ per day and $20 \%$ had 9 to $12 \mathrm{hrs}$ per day.

Table 1: Summary of baseline measures for treatment group

\begin{tabular}{lll}
\hline \multicolumn{1}{c}{ Measurement } & \multicolumn{1}{c}{$\begin{array}{c}\text { Group A } \\
(\mathbf{n = 2 0})\end{array}$} & \multicolumn{1}{c}{$\begin{array}{c}\text { Group B } \\
(\mathbf{n = 2 0})\end{array}$} \\
\hline Age(yrs $)$ & $41.9(28-65)$ & $40.3(29-54)$ \\
Gender M/F & $6 / 14$ & $5 / 15$ \\
Weight( Kg) & $58.8(47-78)$ & $56.9(46-74)$ \\
Body mass index & $22.7(19-26)$ & $21.8(19-26)$ \\
Hours spent standing & $7.7(6-10)$ & $7.6(6-10)$ \\
Duration of symptoms & & \\
10 to 12 months & 8 & 8 \\
13 to 18 months & 12 & 12 \\
19 to 24 months & 0 & 0 \\
\hline
\end{tabular}

Amongst the seven items of Foot function index subscale, Item no 2 (pain during 1st few steps in the morning), which is also the disease defining item was analyzed separately.

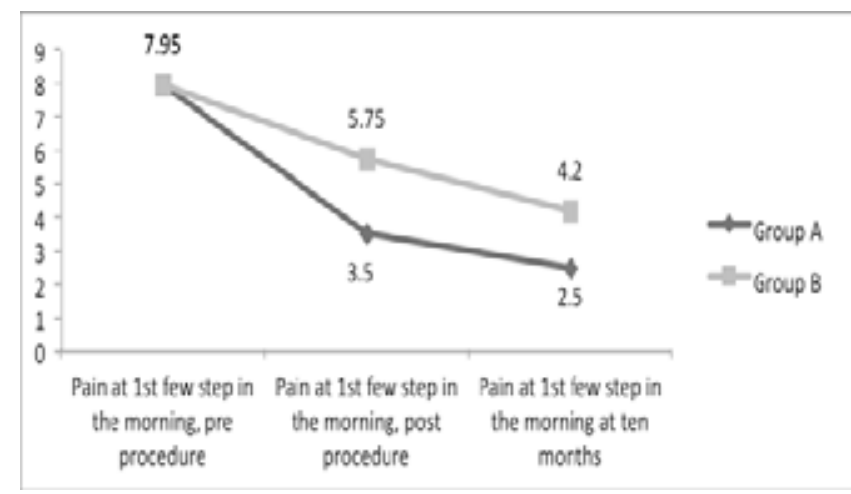

Figure 3: pain subscale for foot function index: Item 2

There was significant improvement of pain at 1st few steps in the morning in both the groups more so in group A (plantar fascia tissue-stretching group). The difference between the two groups was statistically significant at the follow up in 8 weeks and 10 months $(p=0.001$ and $p=0.003$ respectively) and the difference was more marked during the first 8 weeks. 
Table 2

\begin{tabular}{|c|c|c|c|c|c|}
\hline & $\begin{array}{l}\text { Group } \\
\text { Mean }\end{array}$ & $\begin{array}{r}\text { A } \\
\text { SD }\end{array}$ & $\begin{array}{l}\text { Group } \\
\text { Mean }\end{array}$ & $\begin{array}{r}\text { B } \\
\text { SD }\end{array}$ & P value \\
\hline $\begin{array}{l}\text { Pain in } 1^{\text {st }} \\
\text { few steps pre } \\
\text { procedure }\end{array}$ & 7.95 & 0.9 & 7.95 & 0.8 & 1 \\
\hline $\begin{array}{l}\text { Pain in } 1^{\text {st }} \text { few } \\
\text { steps at } 8 \text { weeks }\end{array}$ & 3.5 & 2.4 & 5.75 & 1.4 & 0.001 \\
\hline $\begin{array}{ll}\text { Pain in } 1^{\text {st }} & \text { few } \\
\text { steps at } & 10 \\
\text { months } & \end{array}$ & 2.5 & 1.8 & 4.2 & 1.6 & 0.003 \\
\hline
\end{tabular}

The trend of improvement for the mean of all the items in the foot function subscale revealed improvement in both groups with better results in Group A, persisting through 10 months and more marked difference at 8 weeks period.

Overall assessment of Subject relative outcome measure was done by splitting the responses to either positive or negative. Positive response in group A was 75\% $(\mathrm{p}=0.004)$ and Group B was $30 \%(p=0.004)$ at 8 weeks. Positive response in group A was $85 \%$ and Group B was $50 \%(p=0.018)$ at 10 months.

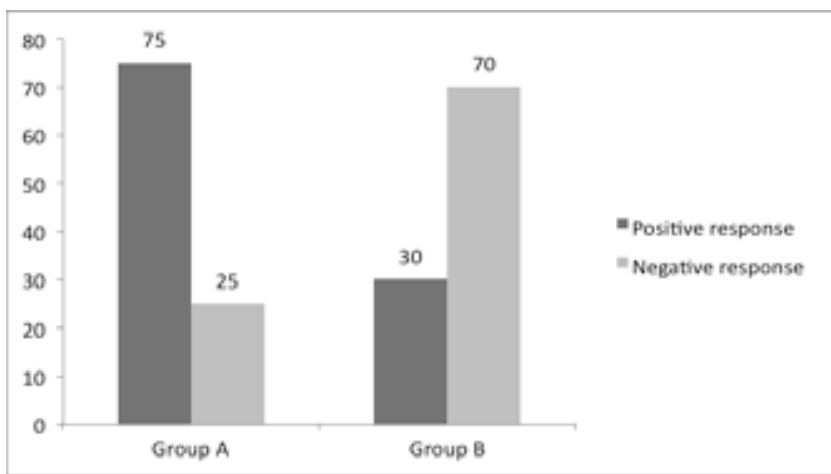

Figure 4: Response at 8 weeks.

Response at 8 weeks was predominantly positive (75\%) in Group A and predominantly negative $70 \%$ ) in group B.

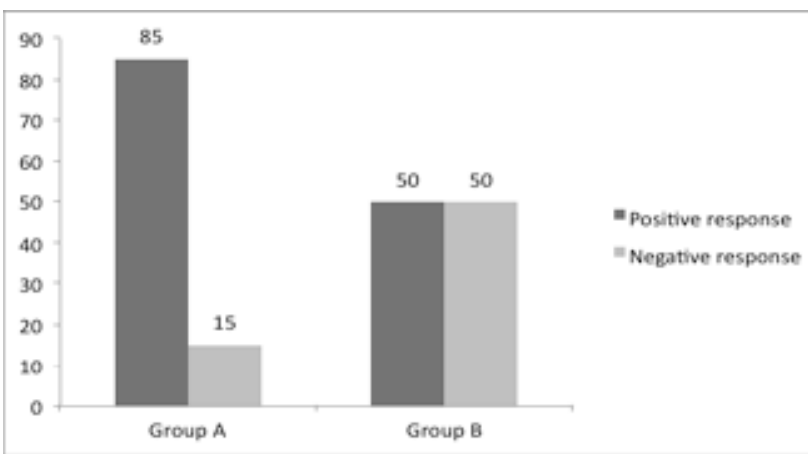

Figure 5: Response at 10 month

Response at 10 months also showed predominantly positive response $(85 \%)$ in group $\mathrm{A}$ and predominantly negative $(50 \%)$ response in group B.

\section{Discussion:}

Chronic plantar fasciitis comprises a significant bulk of patients attending Orthopedics outpatient department. These patients undergo various treatment modalities ranging from NSAIDS, physiotherapy, Orthotics, cortisone injection and even surgery.

According to a study conducted by Digiovani et $\mathrm{al}^{4}$ there was a significant improvement in the outcome of the disease after the exercise that stretched the plantar fascia as compared to the standard weight-bearing Achilles tendon stretching exercises for the treatment of chronic plantar fasciitis. Subsequent study was carried out by the same author with minor changes in team members to study the outcome at two years follows up. This time, the study was done in two phases. First phase consisted of two different exercises and evaluation done after eight weeks. The result was in favour of plantar fascia stretching exercise. In second phase both groups were given same exercise (Plantar fascia stretching exercise) and evaluation done after two years. At two years there was an improvement in the pain score but no difference in the two groups. ${ }^{9}$

In a recent randomized, controlled study of the short and long-term effectiveness of high-energy shock wave treatment for chronic plantar fasciitis, Ogden et al. ${ }^{10}$ reported that $77 \%$ of all patients had good or excellent results, but this kind of modality is not available in Nepal.

Roos E et $\mathrm{al}^{11}$ in 2006 randomized Forty-three patients with plantar fasciitis to receive foot orthoses $(n=13)$, foot orthoses and night splints $(\mathrm{n}=15)$, or night splints alone $(\mathrm{n}=$ 15). Data was collected at12weeks and at 1-year follow-up. Pain, functional limitations, and quality of life was evaluated with the Foot and Ankle Outcome Score. At 12 weeks, pain reduction of $30 \%$ to $50 \%$ compared to baseline were seen (p $<0.03$ ) and at 52 weeks, pain reduction of $62 \%$ was seen in the two groups using foot orthoses compared to $48 \%$ in the night splint only group $(\mathrm{p}<0.01)$. Better compliance was reported for orthoses use. At 12 months, 19 of 28 patients still reported using foot orthoses compared to 1 of 30 still using night splint. They concluded that foot orthoses and night splints were both effective in treating plantar fasciitis, but better compliance of foot orthosis is the best choice for treatment of plantar fasciitis.

Tsai WC et al ${ }^{12}$ studied 25 patients with chronic plantar fasciitis treated with local steroid injection: comparison between sonographic and palpation guidance method was done and it was found that VAS improved significantly after injection $(\mathrm{P}<0.01$ in palpation guided group; $\mathrm{p}<0.001$ in the sonographisally guided group). The recurrence rate of plantar fasciitis in patients of palpation guided group $(6 / 13)$ was significantly higher than the sonographically guided group $(1 / 12)(\mathrm{p}<0.05)$. They concluded that steroid 
injection can be an effective way to treat plantar fasciitis and injection under sonographic guidance is associated with lower recurrence of heel pain. Crawford F et al ${ }^{13}$ studied 106 patients with heel pain treated with steroid injection and found that a statistically significant reduction in pain was detected at one month $(\mathrm{P}=0.02)$, but thereafter no differences could be detected. They concluded that steroid injection can provide relief from heel pain for only a short term.

Cheung JT et al ${ }^{14}$ studied Consequences of partial and total plantar fascia release in treatment of chronic unresponsive heel pain and found decrease in arch height but did not necessarily cause total collapse of foot arch. They predicted load redistribution among the centralized metatarsal bones and relief of focal stress at the calcaneal insertion thereby decreasing associated heel pain after fascia release. However, these operative procedures may pose a risk to arch stability and clinically may produce dorsolateral midfoot pain. Therefore they concluded that treating plantar fasciitis should be non operative initially and if surgery is indicated, partial release of less than $40 \%$ of the fascia is recommended to minimize the effect on arch instability and maintain normal foot biomechanics.

In our study patients with chronic symptoms (more than ten months in duration) were only included and these patients had already undergone other treatment prior to the study. This minimizes the possibility of improvement secondary to time alone.

For patients with chronic plantar fasciitis, this study reinforces the value of plantar fascia stretching method. We believe that it is an important component of treatment and is superior to the conventional Achilles tendon stretching exercise as was thought before. These results provide us with an effective, inexpensive, and straightforward treatment modality before undergoing invasive procedures like steroid injection, partial plantar fascia release or other expensive and cumbersome methods like use of orthoses and ultrasonographic treatment.

\section{Conclusion:}

After eight weeks of treatment, the group managed with plantar fascia stretching exercises exhibited enhanced outcomes with regard to pain, function, and overall satisfaction compared with those of the group managed with standard Achilles tendon stretching exercises. Results at ten months follow up showed continuous progress in both groups but trend of progress was not as steep as in first 8 weeks. This study supports the use of tissue-specific plantar fascia-stretching method as the key component in treatment of chronic plantar fasciitis with an effective, inexpensive, home based and straightforward treatment modality for a developing country like ours.

\section{REFERENCE}

1. Thompson JV, Saini SS, Reb CW, Diagnosis and management of plantar fasciitis. J Am osteopath Assoc 2014;114:900-6.

2. Last AJ, McMinn RMH: Last's Anatomy Regional and applied, 9th ed. NY, Churchill Livingstone 1994.p.196.

3. Miller MD: Review of Orthopaedics, $4^{\text {th }}$ ed.Philadelphia, WB Saunders 2004;p.339.

4. Digiovanni BF, Nawoczenski DA, Lintal M, et al: Tissuespecific Plantar Fascia - stretching exercise enhances outcomes in patients with chronic heel pain. A prospective randomized study: J Bone Joint Surg Am. 2003;85:1270-7.

5. Davis PF, Severund E, Baxter DE. Painful heel syndrome: Results of nonoperative treatment. Foot Ankle Int 1994;15:531-5.

6. Rosenbaum AJ, Di Preta JA, Misener D. Plantar heel pain. Med clin North Am 2014;98:339-52.

7. Tisdel CL, Donley BG, Sferra JJ. Diagnosing and treating plantar fasciitis: a conservative approach to plantar heel pain. Cleve Clin J Med 1999;66:231-5.

8. Pfeffer G, Bacchetti P, Deland J, et al: Comparison of custom and prefabricated orthoses in the initial treatment of proximal plantar fasciitis. Foot Ankle Int 1999;20:214-21.

9. Digiovanni BF, Nawoczensk DA, Malay DP, et al. Plantar Fascia-Specific Stretching Exercise Improves Outcomes in Patients with Chronic Plantar Fasciitis. A Prospective Clinical Trial with Two Year Follow Up. J Bone Joint Surg Am 2006;88:1775-81.

10. Ogden JA, Alvarez R, Levitt R, et al. Shock wave therapy for chronic proximal plantar fasciitis. Clin Orthop Relat Res 2001;387:47-59.

11. Roos E, Engström M, Söderberg B: Foot orthoses for the treatment of plantar fasciitis. Foot Ankle Int 2006;27:606-11.

12. Tsai WC, Hsu CC, Chen CP, et al: Plantar fasciitis treated with local steroid injection: Comparision between sonographic and palpation guidance, J Clin ultrasound 2006;34:12-6.

13. Crawford F, Atkins DP, Young P, et al. Steroid injection for heel pain: evidence of short-term effectiveness, A randomized controlled trial. Rheumatology(oxford). 1999;38:974-7.

14. Cheung JT, An KN, Zhang M: Consequences of partial and total plantar fascia release: a finite element study. Foot Ankle Int 2006;27:125-32. 